\title{
A cross-cultural comparison of population-specific face shape preferences
}

\section{(Homo sapiens)}

\author{
Dariusz. P. Danel ${ }^{1 *}$, Paweł Fedurek ${ }^{2}$, Vinet Coetzee ${ }^{3}$, Ian D.Stephen ${ }^{4}$, Natalia Nowak ${ }^{1}$, \\ Michael Stirrat ${ }^{5}$, David I. Perrett ${ }^{5} \&$ Tamsin K. Saxton $^{6}$
}

${ }^{1}$ Polish Academy of Sciences, Institute of Anthropology, Kuźnicza 35, 50-951 Wrocław, Poland

${ }^{2}$ Department of Psychology, University of York, Heslington, York, YO10 5DD, United Kingdom

${ }^{3}$ Department of Genetics, University of Pretoria, Hatfield, Pretoria 0028, South Africa

${ }^{4}$ School of Psychology, The University of Nottingham, Malaysia Campus, Jalan Broga, 43500 Semenyih,

Selangor Darul Ehsan, Malaysia

${ }^{5}$ School of Psychology, University of St Andrews, St Mary’s Quad, St Andrews, Fife KY16 0HE, United

Kingdom

${ }^{6}$ School of Social and Health Sciences, University of Abertay Dundee, Bell Street

Dundee DD1 1HG, United Kingdom

${ }^{*}$ Corresponding author:

Dariusz P. Danel

e-mail: danel@antro.pan.wroc.pl

Institute of Anthropology

Polish Academy of Sciences

Ul. Kuźnicza 35

50-951 Wrocław, Poland

Tel. +487134386 75, Fax +48 713438150

Running title: A cross-cultural comparison of population-specific face shape preferences. 


\begin{abstract}
A substantial number of studies indicate that human facial features such as symmetry and averageness are preferred in human mate choice. Little is known, however, about face preferences in intra-population or between-cultural settings as only a few studies have addressed this topic. One hypothesis is that people prefer faces that resemble faces from their own population as a result of visual adaptation. Here we present results of an internet-based experiment in which male and female participants from two European nations, Poland and Scotland, were asked to choose between 'Polish-modified' and 'Scottish-modified' faces (i.e. face portraits modified along one of ten different dimensions to resemble faces of the respective populations) of both sexes while being unaware of the origins of the portraits. The results show that the preferences of Polish judges towards Polish-shaped faces were significantly stronger than the preferences of Scottish judges towards the Scottish-shaped faces. Moreover, both Polish and Scottish judges preferred Polish-shaped faces above Scottish-shaped faces. These results suggest that natural visual experience acquired in everyday interpersonal interactions may have limited influence on aesthetic preferences in these particular intra-population settings.
\end{abstract}

\title{
Introduction
}

In humans, the face is one of the most important traits affecting mate preferences and mate choice (e. g. Grammer et al. 2003; Peters et al. 2007; Currie \& Little 2009) and corresponds to an individual's overall attractiveness (Saxton et al. 2009a). Faces primarily focus one's attention while observing both men and women (Hewig et al. 2008) and facial attractiveness can be assessed almost immediately (even after 13ms), on the base of limited information 
(Olson \& Marshuetz 2005 see also: Willis \& Todorov, 2006). It is also well documented that there is general cross-cultural agreement on beauty standards and physical attractiveness (e.g. Perrett et al. 1994; Cunningham et al. 1995; Langlois et al. 2000). However there is still considerable debate concerning the mechanisms guiding the assessment of facial beauty and the relative role of cross-cultural differences in this respect (reviews: Penton-Voak \& Perrett 2000; Kościński 2008; Little et al. 2011).

Two of the possible mechanisms underlying variability in facial preferences are the mere "exposure effect" and "visual adaptation phenomenon" (see: Little et al. 2011). According to the first paradigm, repeated exposure to stimuli increases preferences for them and subliminal stimuli may induce stronger exposure effects than more conscious stimuli perception (Zajonc 1968; Bronstein 1989; Zajonc 2001). Similarly, initial visual experience with a given type of priming stimuli such as faces is thought to modify neural responses and lead to after-effects that bias the perception of novel objects (Leopold et al. 2001; Rhodes et al. 2004; Webster et al. 2004; Little et al. 2005; for more discussion on the dynamic of visual adaptation see: Leopold et al. 2005). A good example of visual adaptation is the calibration of facial attractiveness perception after exposing participants to a series of similar looking faces. Observers tend to prefer the face shape they were exposed to during the initial adaptation phase when given a choice of various different face shapes in a follow up study (Rhodes et al. 2003 also see: Re at al., in press; Little et al. 2005; Cooper \& Maurer 2008; Jones et al. 2008). This mechanism seems to be operating both in adults and, although less sensitively, in preadolescent children (Anzures et al. 2009).

It is important to note that both of the above mechanisms influencing face preferences highlight the role of perceived face familiarity in these preferences. In a real world situation 
this might suggest that faces which come from the same population as observers may be preferred more. For instance, Saxton, Little, DeBruine, Jones, \& Roberts (2009b) showed that exposure to male and female faces in single-sex and mixed-sex schools was associated with modified adolescents' preferences for facial sexual dimorphism. When compared with pupils at coeducational schools, those at single-sex schools preferred more strongly the faces that possessed cues of sexual dimorphism (i.e. feminity or masculinity) that were congruent with the gender of their school peers.

This perceptual system operating on facial preferences that is relatively sensitive to visual exposure might be successfully investigated in the contexts of global social processes such as international migrations. Indirect support for this can be found in a study by Webster et al. (2004) on Caucasian and Asian faces. As the authors demonstrated both in the laboratory and in routine daily conditions, visual adaptation and experience with different ethnicities results in a shift in the categorical boundary for perceived facial ethnicity (Webster et al. 2004). Thus, assuming no prior interaction and no cues regarding individuals' descent, it can be hypothesized that outsiders to a population, might be preferred less by local populations since their face configurations are novel and unfamiliar to the own-population.

In order to test this hypothesis we set up an on-line experiment investigating preferences towards several composite faces whose appearance had been modified to reflect the morphology of two European nations, that is Scotland and Poland. We selected these nations because both Scottish and Polish people belong to the Caucasian race. Although the Polish and Scottish populations are geographically separated they both share common physical characteristics such as, for instance, relatively narrow faces and noses, light skin tones, high variability of hair and eye colours, and similar anatomy of the eye area (e.g. Malinowski 
1999). Although previous research found that facial morphology of diverse populations even within one racial group can differ significantly (Hajniš et al. 1994) these general similarities may suggest that possible differences in face preferences will not be detectable for observers. If they were, however, this may indicate that perceptual mechanisms are sensitive not only in other-race conditions (see: Webster et al. 2004) but also in more narrow intra-racial scales.

When conducting cross-cultural studies one possible factor that may modify the character of out-group/in-group aesthetic and partner preferences is internalization of sociocultural standards and ethnocentrism (Li et al. 2002; Glauert et al. 2009). Also other authors (Levin et al. 2007) indicate that, the attitude to other groups, intergroup anxiety and group identification can influence dating decisions. Accordingly our study also set out to test whether in-group identification moderates facial preferences.

The main aim of the present study is to examine whether facial preferences of two nations belonging to the same race i.e. Poland and Scotland, could be affected by the morphological own-group vs. stranger-group facial features. Here we report only these results which consider facial attractiveness judgements while controlling for possible covariates such as several in-group identification measures which may influence people's behaviour and owngroup/stranger-group attitudes (Leach et al. 2008 and citations therein).

\section{Methods}

Stimuli

We collected digital facial photographs of 33 Polish (18 females, 15 males) and 34 Scottish (17 females, 17 males) young adults. The stimuli preparation and modification were carried out in several steps using the in-house face processing software "Psychomorph" (Rowland \& 
Perrett 1995; Tiddeman et al. 2001). First, we constructed 10 target composite faces (5 male; 5 female), by averaging four individual images (2 Scottish; 2 Polish) for each composite. We also constructed 10 pairs of Polish and Scottish facial prototypes by averaging images of three Polish or Scottish individuals who were always different from those in the corresponding target faces. Next, each composite target faces were shape-transformed by transforming the target composite along the dimension defined by just one of the ten pairs of Polish-Scottish prototypes. For each shape transform the composite face was transformed by $40 \%$ of the difference between the Polish and Scottish prototypes. This degree of transformation yielded noticeable shape-modification of target composites reducing at the same time the probability of appearance of undesirable graphic artefacts (if any subtle graphic distortion appeared e.g. in nostril clarity or smoothens of the eyelid lines, they were meticulously retouched using GIMP 2.6.7, GNU Image Manipulation Program: www.gimp.org). Each prototype was used in just one transformation, with the aim of avoiding over-reliance on just one dimension of difference between Scottish and Polish faces. Transformations were shape only and did not include colour changes. To exclude possible influence of non-facial traits (i.e. hair, neck, ears) on preferences all images were masked after transformations. This procedure generated 10 pairs of $40 \% \mathrm{POL}$ (images manipulated $40 \%$ in shape towards the Polish faces) and $40 \% \mathrm{SCO}$ (images manipulated $40 \%$ in shape towards the Scottish faces) modified faces in total (Fig. 1). The pairs of faces were placed on the Internet and presented side-by-side in a random order using a Java applet.

Stimuli validation

In order to determine if the effect of face shape-transformation was noticeable, ten pairs of modified faces were presented to 39 Scottish $($ mean age $=23.85$, s.d. $=7.82)$ and 48 Polish 


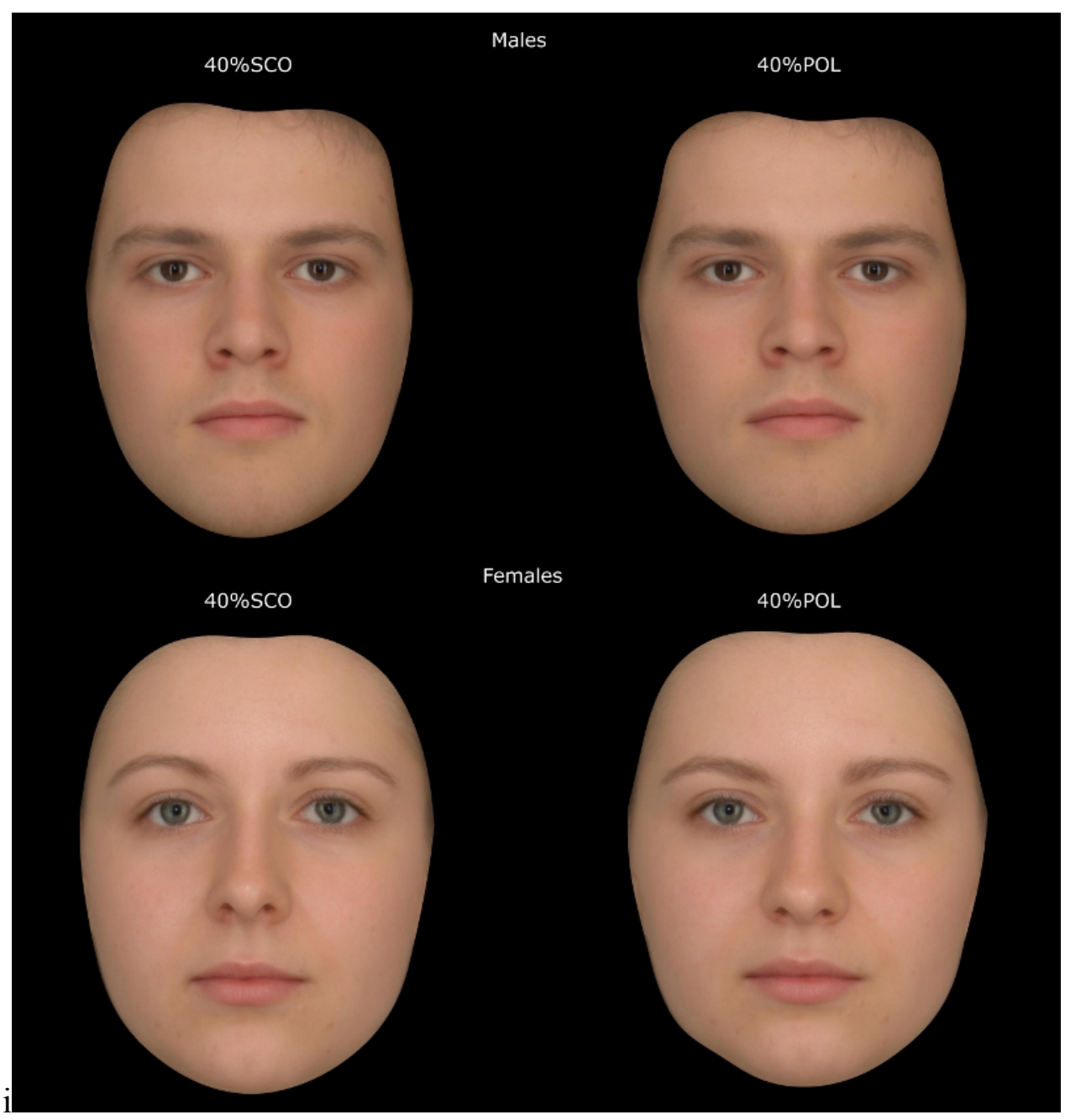

Fig. 1: Examples of pairs of male (top row) and female (bottom row) faces transformed towards Scottish (left column) and Polish (right column) face shapes. Transformation dimensions differed for each pair (see Methods/Stimuli).

individuals (mean age $=34.0$, s.d. $=6.82)$. Participants were asked to indicate which face in each pair they perceived as more familiar. We deliberately avoided asking directly about Scottishness and Polishness of the faces because results from a pilot study revealed that these type of questions may activate stereotype-like thinking and therefore bias face perception. The analysis revealed that participants chose faces which were congruent with their nationality as more familiar significantly more often than it was expected by chance [average proportion of 
faces which were chosen accordingly to the judge's nationality $57,24 \%$ vs. chance value $50.0 \%$; Wilcoxon signed-rank test: $Z=3.18 ; \mathrm{p}=.001]$ and the sizes of the effects triggered by the transformation on face classification did not differ for Scottish and Polish raters [average proportions of faces chosen accordingly to the Scottish and Polish nationality (54,36 vs. 59.58 respectively $) ;(\mathrm{df}: 85)=1.22, \mathrm{p}=0.23]$

Participants

In Scotland the experiment ran in English through the website of St. Andrews University Psychology Department Perception Lab (www.perceptionlab.com), a site that regularly advertises psychology experiments and attracts many visitors. The study in Poland was advertised to students in two Polish universities (biology and psychology students of the University of Wrocław and the Warsaw School of Social Sciences and Humanities) and also to the readers of a Polish internet-based popular-science magazine (www.kopalniawiedzy.pl). To conceal the fact that the experiment was based outside Poland, Polish participants used a Polish-domain website hyperlink which redirected them to a Polish language version of the study. The experiment was restricted to Polish and Scottish adult nationals who had stayed at least three years in their home countries before they took part in the experiment. Due to the particular aim of the study, data obtained only from those who assessed their ethnicity as Caucasians were included into the final analyses. These selection criteria resulted in a sample size of 84 Polish citizens ( 39 female: mean age $=25.4$, s.d. $=6.47$ and 45 male: mean age $=$ 27.2, s.d. $=8.70)$ and 48 Scottish citizens ( 32 female: mean age $=21.2$, s.d. $=4.69 \& 16$ male: mean age $=22.7$, s.d. $=6.88)$ who completed the preference test and all the questions (twelve participants omitted at least one question in the survey). 
Procedure.

All participants accepted the study terms and conditions (i.e. aged 18 or over, Polish or Scottish place of residence) and gave informed consent for participating in the study. Secondly, using their own computers they completed a face preference test by clicking on one of the transformed faces from each pair of faces (40\%POL vs. $40 \% \mathrm{SCO})$ to indicate which of the two transformed images they found more attractive. Next, they reported their age, sex, ethnicity and indicated whether they had been living in Poland/Scotland for at least the past three years. Moreover, to establish one's identification with their nation, which may possibly affect an individual's feelings and behaviour and consequently influence his/her attitude to unfamiliar faces, participants also completed an in-group identification questionnaire designed by Leach et al. (2008). This questionnaire conceptualizes two dimensions of an individual's in-group identifications. First, self definition which is measured by (i) individual self-stereotyping (i.e. perceiving oneself as similar to average group member) and (ii) ingroup homogeneity (i.e. perceiving oneself as a member of a coherent but distinctive group). The second dimension, self-investment, is indicated by in-group identification components such as (i) satisfaction (i.e. describing positive feelings about one's group); (ii) solidarity (i.e. reflecting a psychological link and commitment to one's group); and (iii) centrality (i.e. reflecting sensitivity to external threats to the group). Non-parametric tests were used where data did not satisfy assumptions of parametric analyses. Analyses were carried out in STATISTICA, version 10, (www.statsoft.com).

\section{Results.}

The Mann-Whitney U tests revealed statistically significant differences between Polish and Scottish participants in three out of five in-group identification measures (all statistics are 
shown in Table 1). While Scots had a significantly higher level of in-group solidarity and individual self-stereotyping than their Polish counterparts, Poles had a significantly higher level of in-group homogeneity than the Scottish participants. In-group centrality and Satisfaction did not differ significantly between the two nations. Solidarity, self-stereotyping and in group homogeneity were included in the main analysis as covariates.

Table 1: Differences between Polish and Scottish participants in the in-group identification measures.

\begin{tabular}{|c|c|c|c|c|c|c|}
\hline \multirow[t]{2}{*}{ In-group identification measure } & \multicolumn{2}{|c|}{ Polish judges, $n=84$} & \multicolumn{2}{|c|}{ Scottish judges, $\mathrm{n}=48$} & \multirow[t]{2}{*}{$\mathrm{Z}$} & \multirow[t]{2}{*}{$p$} \\
\hline & Mean & Standard deviation & Mean & Standard deviation & & \\
\hline Solidarity & 14.1 & 4.70 & 15.9 & 3.53 & -2.08 & 0.04 \\
\hline Satisfaction & 20.1 & 5.89 & 22.0 & 4.63 & -1.76 & 0.08 \\
\hline Centrality & 11.6 & 5.18 & 12.4 & 4.80 & -0.69 & 0.49 \\
\hline Individual self-stereotyping & 7.2 & 2.85 & 8.5 & 2.43 & -2.40 & 0.02 \\
\hline In-group homogenity & 8.9 & 2.63 & 8.0 & 2.40 & 2.38 & 0.02 \\
\hline
\end{tabular}

The main analysis was carried out by employing a mixed model ANOVA with sex of the target face (same or opposite-sex to rater) as a within subject factor; rater's sex and nationality (Polish or Scottish) as between-subject factors and solidarity, individual self-stereotyping and in-group homogeneity as covariates. The dependent variable expressed the proportion of times (out of five both for male and female faces) that each participant chose the face whose shape was manipulated towards the prototype face shape of the participant's own nationality. The analysis revealed only one significant main effect. Poles in general chose a significantly greater proportion of the faces that were modified to resemble their compatriots than Scots $[57.89 \%$ vs. $35.94 \% ; F(1,125)=37.26, \mathrm{p}<0.00001]$ (Fig 2$)$. All other main effects and interactions as well as the effects of covariates were non-significant (all $p>0.15$ ). 
Additionally, in order to test whether the magnitude of Scottish and Polish preferences was significantly different in the two groups of raters the design of the analysis was modified by changing the dependent variable to express the proportion of Polish faces preferred by both groups of judges. This analysis revealed that the proportion of preferred $40 \% \mathrm{POL}$ faces were significantly higher in Scottish than in Polish judges $[64.06 \%$ vs. $57.89 \% ; F(1,125)=4.83$, p $=0.03]$. All other main effect, interactions and effects of covariates were non-significant (all $p$ $>0.12)$.

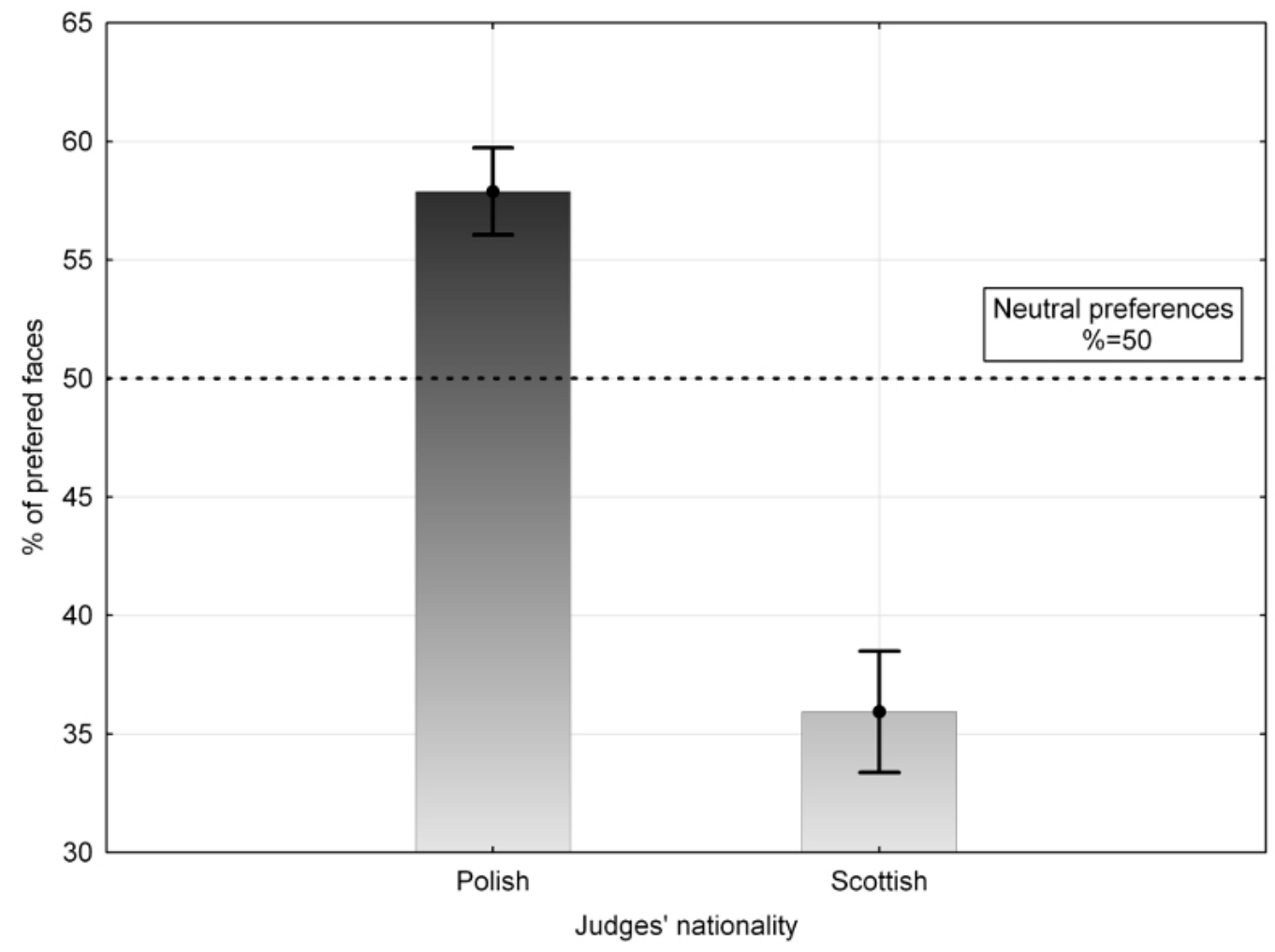

Fig. 2: Preferences towards faces which shapes were modified to resemble participants' nationality. Bars $=$ mean $+/-\mathrm{SE}$

It should be noted however that the difference between the above proportions does not prove unambiguously that preferences were significantly and systematically (better than expected by chance; dotted lines in Figures 2 and 3) biased toward one or other nation. To confirm this we 
conducted two separate Wilcoxon signed-rank tests for Polish and Scottish judges, with the percentage of trials (10 in total i.e. 5 pairs of portraits for females and 5 for males) in which a particular judge chose the face modified towards his/her nationality. The Wilcoxon signedrank tests showed that both Polish $[Z=4.03, \mathrm{p}<0.0001]$ and Scottish $[Z=4,45 \mathrm{p}<0.00001]$ participants preferred the $40 \% \mathrm{POL}$ transforms significantly more often than expected by chance. In other words, there was a significant bias in judges' preferences toward faces transformed towards more Polish appearance. This conclusion was also supported by the additional analysis comparing the frequencies of those participants who preferred more often i) foreign faces (i.e. less than 5/10 faces congruent with participants' nationality), ii) faces matching rater's nationality (i.e. more than 5/10 faces congruent with participants' nationality) and iii) those who did not show biases in preference (i.e. preferred exactly 5 faces congruent with participants' nationality). In particular, among Polish participants $63.10 \%$ preferred mostly $40 \%$ POL faces, $21.43 \%$ preferred in most cases $40 \%$ SCO and $15.47 \%$ did not show any direction in preferences. These differences were statistically significant [Cochran $Q(\mathrm{df}: 2)$ $=33.93, \mathrm{p}<0.00001]$ and post-hoc multiple comparisons by sign tests (Bonferroni corrected) revealed that the differences between proportions of those participants who mostly preferred $40 \% \mathrm{POL}$ faces and proportions of two other groups were statistically significant [for both cases: $Z>4.04, \mathrm{p}<0.001]$. The proportion of Polish raters who preferred in most cases $40 \% \mathrm{SCO}$ faces did not differ from the proportion of those whose preferences were unspecified $[Z=0.72, \mathrm{p}>0.05]$ (Fig.3). Similarly the majority i.e. $70.84 \%$ of Scottish participants preferred mostly foreign, 40\%POL faces and observed differences were statistically significant [Cochran $Q(\mathrm{df}: 2)=30.38, \mathrm{p}<0.00001]$. The frequencies of those who preferred in most choices $40 \% \mathrm{SCO}$ faces, and those with unspecified direction of preferences were identical and came to $14.58 \%$. The post-hoc sign tests for multiple comparisons showed (after Bonferroni correction) that those who mostly preferred 40\%POL faces constituted a 
statistically significant majority in Scottish participants when individually compared with the two other groups [for both cases: $Z=4.06, \mathrm{p}<0.001$ ] (Fig. 3).

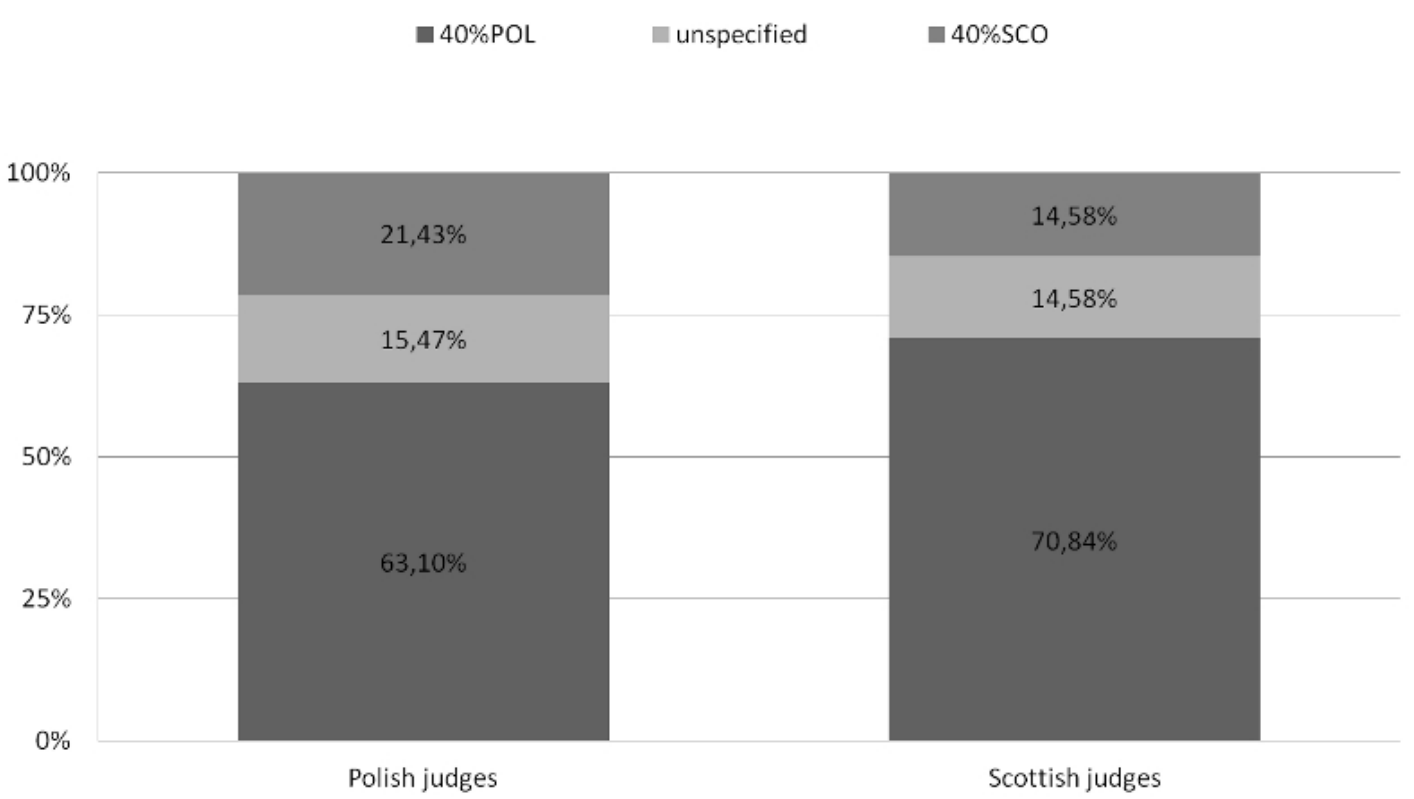

Fig 3. Distribution of preferences in Polish and Scottish participants.

\section{Discussion}

The results of our cross-cultural study on face preferences shows two statistically significant outcomes. First, the preferences of Polish judges towards portraits modified to resemble prototype Polish face shapes were significantly stronger than the preferences of Scottish judges towards the Scottish facial shapes. Secondly, the preferences of all judges were unidirectionally biased, meaning that both nations preferred Polish face morphology. Note that instead of relying only on one Polish-Scottish morphological dimension of face transformation we used diverse axes of transformation defined by several pairs of different prototype faces. The validation study confirmed that this procedure produced faces which appearance was assessed significantly more often than a chance as more familiar, congruently with the rater's nationality. This methodology differs from the ones used in previous studies 
which tended to use in the face manipulation procedure only one dimension of face transformation determined by two, usually substantially averaged, types of facial morphology. However, since perfectly average face, seems to be rather a mathematical concept than a real phenomenon, relying on one dimension of differences in facial morphology may to some extent hinder face transformation procedure i.e. by over resemblance modified faces to each other. Using multiple, different prototype faces and consequently multiple axes of face modification provide more variability in the final shapes of transformed stimuli and, in our opinion, made the experiment condition closer to natural ecological conditions.

There are several studies on a visual adaptation phenomenon which have been conducted in natural and contemporary human ecological settings. For instance, in the study on developmental changes in perception of facial attractiveness Cooper, Geldart, Mondloch \& Maurer (2006) showed that the experience with the proportion of internal features of faces acquired in the course of everyday interaction with children and/or adults may affect perception of facial beauty. The results also indicate that the adult like pattern for judgements of attractiveness is acquired gradually. Therefore it cannot be ruled out that in children not only the facial-morphology-related norm-based coding processes but also other factors (e.g. development of face processing skills, developmental changes in the perspective from which the faces are viewed) may interact with the mere effect of visual exposure (for more discussion see: Cooper et al. 2006). Also other works suggest that 'natural' visual experience may affect adolescents' preferences to sexual dimorphism (Saxton et al. 2009c) as well as perception of ethnic boundaries along Asian-Caucasian continuum (Webster et al. 2004). However the results of both of the above studies might be affected by very clear-cut exposure conditions (female vs. male, or Caucasian vs. Asian faces) that may generate possible aftereffects. Referring to our results we suggest that in relatively subtle intra-racial conditions and 
in an environment abundant in multiple every-day interpersonal contacts the exposure effects to own/stranger-clique faces might be relatively weak. This conclusion corresponds with the results from the facial-based ethnic recognition study by Coetzee et al. (2009a). Relying on facial images, individuals relatively highly ethnically intermixed and with a high level of every-day visual exposure to members of different ethnicities, could not reliably differentiate between the members of two closely related but ethnically distinct groups in South Africa. Although, an improvement in facial recognition skills might be enhanced by a greater exposure to variation of facial morphology i.e. by family environment of ethnically mixed individuals (Coetzee et al. 2009a), the results suggest that the general mechanism of facial perception in some conditions may be insensitive to the subtle differences in facial morphology. Furthermore, other authors (Jaquet et al. 2007; Bestelmeyer et al. 2008) also showed that after-effects resulting from visual adaptation can operate only in distinctive perceptual face categories (e.g. male vs female; different races ) but not within one perceptually homogenous category (e.g. female vs hyper-female; within one race category). From a more general perspective, lack of populational congruency in attractiveness assessment indicates that when no cues other than visual ones are available, preferences of men and women towards facial morphology in a given population cannot be unambiguously explained by an individual's place of origins or residence. This also gives an additional insight into the role of visual adaptation processes (see e.g.: Rhodes et al. 2003) and suggests that in routine-daily conditions other effects may have a greater influence on facial attractiveness judgments. The unidirectional nature of facial preferences revealed by our complementary analysis suggests that they may be triggered by some widespread universal cues of attractiveness that, at least for Scottish participants, may override visual adaptation effects. For instance, among several morphological markers of facial attractiveness, averageness and symmetry seem to be universally preferred by both sexes and in cross-cultural contexts 
(Rhodes 2006; Little et al. 2011). Similarly, facial cues of adiposity may additionally modify shape preferences since perceived body weight is significantly associated with measures of actual health as well as perceived health and attractiveness (Coetzee et al. 2009b; Coetzee et al. 2010). In the current study we did not explicitly allow for the role of facial attractiveness markers and possible consistent differences between them in two analysed populations. Therefore it cannot be ruled out that calibration of preferences on some universal markers of beauty might be reflected in our results.

On the other hand, when discussing possible link between visual adaptation and individual preferences, it is also worth noting that the effects of visual adaptation on the perception of attractiveness may be overrated. For instance, DeBruine et al. (2007) demonstrated that visual adaptation to non-average attractive facial morphology may increase assessment of the normality (perceived averageness) of the attractive faces but at the same time decrease the assessment of their attractiveness (e.g. by making them more prototypical and decreasing their novelty). In other words, visual adaptation may affect perception of different facial characteristics independently of the perception of attractiveness. Further studies on visual adaptation that directly analyse the effects of particular cues of beauty on facial perception may reveal how the natural experience with faces is weighted against other factors possibly affecting aesthetic preferences.

Prior to the commencement of our study we had predicted that an individual's in-group identity may influence beauty preferences. It is well known that Scots have a great level of self-identity and cultural autonomy (Cohen 1996; McCrone 2005). Some researchers showed that prior expressions of intergroup discrimination activate Scottish national stereotyping (Rutland \& Brown 2001). Scottish self-categorization may be also context-dependent. For 
instance, Rutland and Cinirella (2000) showed that European identity of Scots may be negatively influenced when they stereotype their own nation after stereotyping two other European nations (i.e English and Germans) but not after stereotyping Australians. Moreover, our preliminary analyses showed that Polish and Scottish judges differed in three aspects of in-group identification. Scots had a higher level of solidarity and individual-self stereotyping which indicated a stronger link and commitment to their compatriots as well as stronger identification with the "average member" of the Scottish nation. Poles, on the other hand, perceived themselves as a more coherent and distinctive group which was reflected in the higher assessment of in-group homogeneity (see: Leach et al. 2008). Nonetheless, despite these significant differences we did not observe in the main analysis any significant impact of all of the three measures of in-group identity on facial preferences. Our participants were 'blind' to the way of portrait modification (i.e. they were unaware of the direction of shape modification) and this may have resulted in a situation in which the mechanisms of in-group identification in the two compared groups were inactive during the experiment.

In summary, the results of our experiment suggest that in a natural 'real-world' environment (as opposed to laboratory conditions) the role of visual adaptation in facial preferences towards different nations from the same race may be limited. We propose that relatively high level of morphological similarity of faces belonging to a perceptually homogenous group, such as the Caucasian race, may not activate preferences mediated by the visual experience effects. Alternatively, other factors (e.g. cross-culturally universal markers of facial beauty), that potentially influence the perception of facial attractiveness and that were not analysed in this study may offset the effects of visual experience in aesthetic preferences. Since beauty preferences towards own vs. stranger individuals may have significant social consequences especially in the recent era of globalisation and mass-migrations, more studies are needed to 
explain more explicitly the role of universal and cross-cultural mechanisms responsible for the perception of physical attractiveness.

\section{Acknowledgements.}

We thank Lesley Ferrier, Aleksandra Gomuła, Enya Gillen, Robyn Seymour, and Kerry Harcus for all technical assistance which was extremely valuable in the course of study.

\section{Literature Cited}

Anzures, G., Mondloch, C. J. \& Lackner, C. 2009: Face adaptation and attractiveness aftereffects in 8-year-olds and adults. Child Dev. 80, 178-191.

Bestelmeyer, P. E., Jones, B. C., Debruine, L. M., Little, A. C., Perrett, D. I., Schneider, A., Welling, L. L. \& Conway, C. A. 2008: Sex-contingent face aftereffects depend on perceptual category rather than structural encoding. Cognition 107, 353-365.

Bronstein, R. F. 1989: Exposure and effect: Overwiev and meta-analysis of reseach, 19681987. Psychol. Bull. 106, 265-289.

Coetzee, V., Chen, J., Perrett, D. I. \& Stephen, I. D. 2010: Deciphering faces: quantifiable visual cues to weight. Perception 39, 51-61.Coetzee, V., Greeff, J. M., Barrett, L. \& Henzi, P. 2009a: Facial-based ethnic recognition: insights from two closely related but ethnically distinct groups. S. Afr. J.Sci. 105, 464-466.

Coetzee, V., Perrett, D. I. \& Stephen, I. D. 2009b: Facial adiposity: a cue to health? Perception 38, 1700-1711.Cohen, A. P. 1996: Personal nationalism: a Scottish view of some rites, rights, and wrongs. Am. Ethnol. 23, 802-815.

Cooper, P. A., Geldart, S. S., Mondloch, C. J. \& Maurer, D. 2006: Developmental changes in perceptions of attractiveness: a role of experience? Dev. Sci. 9, 530-543. 
Cooper, P. A. \& Maurer, D. 2008: The influence of recent experience on perceptions of attractiveness. Perception 37, 1216-1226.

Cunningham, M. R., Roberts, A. R., Barbee, A. P., Druen, P. B. \& Wu, C.-H. 1995: "Their ideas of beauty are, on the whole, the same as ours" Consistency and variability in the cross-cultural perception of female physical attractiveness. J. Pers. Soc. Psychol. 68, 261-279.

Currie, T. E. \& Little, A. C. 2009: The relative importance of the face and body in judgments of human physical attractiveness. Evol. Hum. Behav. 30, 409-416.

DeBruine, L. M., Jones, B. C., Unger, L., Little, A. C. \& Feinberg, D. R. 2007: Dissociating averageness and attractiveness: Attractive faces are not always average. J Exp. Psychol. Human 33, 1420-1430.

Glauert, R., Rhodes, G., Byrne, S., Fink, B. \& Grammer, K. 2009: Body dissatisfaction and the effects of perceptual exposure on body norms and ideals. Int. J. Eat. Disord. 42, 443-452.

Grammer, K., Fink, B., Oslash, Ller, A. P. \& Thornhill, R. 2003: Darwinian aesthetics: sexual selection and the biology of beauty. Biol. Rev. 78, 385-407.

Hajniš, K., Farkas, L. G., Ngim, R. C. K., Lee, S. T. \& Venkatadri, G. 1994: Racial and ethnic morphometric differences in the craniofacial complex. In: Anthropometry of the head and face, 2nd edn. (Farkas, L. G., ed). Raven Press, New York.

Hewig, J., Trippe, R., Hecht, H., Straube, T. \& Miltner, W. 2008: Gender differences for specific body regions when looking at men and women. J. Nonverbal Behav. 32, 6778.

Jaquet, E., Rhodes, G. \& Hayward, W. G. 2007: Opposite aftereffects for Chinese and Caucasian faces are selective for social category information and not just physical face differences. Q. J. Exp. Psychol. 60, 1457-1467. 
Jones, B., Debruine, L. \& Little, A. 2008: Adaptation reinforces preferences for correlates of attractive facial cues. Vis. Cogn. 16, 849-858.

Kościński, K. 2008: Facial attractiveness: Variation, adaptiveness and consequences of facial preferences. Anthropol. Rev. 71, 77-105.

Langlois, J. H., Kalakanis, L., Rubenstein, A. J., Larson, A., Hallam, M. \& Smoot, M. 2000: Maxims or myths of beauty? A meta-analytic and theoretical review. Psychol. Bull. 126, 390-423.

Leach, C. W., van Zomeren, M., Zebel, S., Vliek, M. L., Pennekamp, S. F., Doosje, B., Ouwerkerk, J. W. \& Spears, R. 2008: Group-level self-definition and self-investment: a hierarchical (multicomponent) model of in-group identification. J. Pers. Soc. Psychol. 95, 144-165.

Leopold, D. A., O'Toole, A. J., Vetter, T. \& Blanz, V. 2001: Prototype-referenced shape encoding revealed by high-level aftereffects. Nat. Neurosci. 4, 89-94.

Leopold, D. A., Rhodes, G., Muller, K. M. \& Jeffery, L. 2005: The dynamics of visual adaptation to faces. P. Roy. Soc. Lond. B Bio. 272, 897-904.Levin, S., Taylor, P. L. \& Caudle, E. 2007: Interethnic and interracial dating in college: A longitudinal study. J. Soc. Pers. Relat. 24, 323-341.

Li, N. P., Bailey, J. M., Kenrick, D. T. \& Linsenmeier, J. A. 2002: The necessities and luxuries of mate preferences: testing the tradeoffs. J. Pers. Soc. Psychol. 82, 947-955.

Little, A. C., DeBruine, L. M. \& Jones, B. C. 2005: Sex-contingent face after-effects suggest distinct neural populations code male and female faces. P. Roy. Soc. Lond. B Bio. 272, $2283-2287$.

Little, A. C., Jones, B. C. \& DeBruine, L. M. 2011: Facial attractiveness: evolutionary based research. Philos. T. Roy. Soc. B 366, 1638-1659. 
Malinowski, A. 1999: Wstęp do antropologii i ekologii człowieka, 2nd ed. Wydawnictwa Uniwersytetu Łódzkiego, Łódź.

McCrone, D. 2005: Cultural capital in an understated nation: the case of Scotland. Br. J. Sociol. 56, 65-82.

Olson, I. R. \& Marshuetz, C. 2005: Facial attractiveness is appraised in a glance. Emotion 5, 498-502.

Penton-Voak, I. S. \& Perrett, D. I. 2000: Consistency and individual differences in facial attractiveness judgements: an evolutionary perspective. Soc. Res. 67, 219-244.

Perrett, D. I., May, K. A. \& Yoshikawa, S. 1994: Facial shape and judgements of female attractiveness. Nature 368, 239.

Peters, M., Rhodes, G. \& Simmons, L. W. 2007: Contributions of the face and body to overall attractiveness. Anim. Behav. 73, 937-942.

Re, D., Coetzee, V., Xiao, D., Buls, D., Tiddeman, B., Boothroyd, L. \& Perrett, D. Viewing heavy bodies enhances preferences for facial adiposity. J. Evol. Psychol. 9, 295-308.

Rhodes, G. 2006: The evolutionary psychology of facial beauty. Annu. Rev. Psychol. 57, 199226.

Rhodes, G., Jeffery, L., Watson, T. L., Clifford, C. W. G. \& Nakayama, K. 2003: Fitting the mind to the world: face adaptation and attractiveness aftereffects. Psychol. Sci. 14, $558-566$.

Rhodes, G., Jeffery, L., Watson, T. L., Jaquet, E., Winkler, C. \& Clifford, C. W. G. 2004: Orientation-contingent face aftereffects and implications for face-coding mechanisms. Curr. Biol. 14, 2119-2123.

Rowland, D. A. \& Perrett, D. I. 1995: Manipulating facial appearance through shape and color. IEEE Comput. Graph. 15, 70-76. 
Rutland, A. \& Brown, R. 2001: Stereotypes as justifications for prior intergroup discrimination: Studies of Scottish national stereotyping. Eur. J. Soc. Psychol. 31, 127141.

Rutland, A. \& Cinnirella, M. 2000: Context effects on scottish national and european selfcategorization: the importance of category accessibility, fragility and relations. Brit. J. Soc. Psychol. 39, 495-519.

Saxton, T. K., Burriss, R., Murray, A., Rowland, H. \& Craig Roberts, S. 2009a: Face, body and speech cues independently predict judgments of attractiveness. J. Evol. Psychol. 7, 23-35.

Saxton, T. K., Debruine, L. M., Jones, B. C., Little, A. C. \& Roberts, S. C. 2009b: Face and voice attractiveness judgments change during adolescence. Evol. Hum. Behav. 30, 398-408.

Saxton, T. K., Little, A. C., DeBruine, L. M., Jones, B. C. \& Roberts, S. C. 2009c:

Adolescents' preferences for sexual dimorphism are influenced by relative exposure to male and female faces. Pers. Indiv. Differ. 47, 864-868.

Tiddeman, B., Burt, D. M. \& Perrett, D. 2001: Computer graphics in facial perception research. IEEE Comput. Graph. 21, 42-50.

Webster, M. A., Kaping, D., Mizokami, Y. \& Duhamel, P. 2004: Adaptation to natural facial categories. Nature 428, 557-561.

Willis, J. \& Todorov, A. 2006: First impressions: making up your mind after a 100-ms exposure to a face. Psychol. Sci. 17, 592-598.

Zajonc, R. B. 1968: Attitudinal effects of mere exposure. J. Pers. Soc. Psychol. 9, 1-27.

-. 2001: Mere exposure: A gateway to the subliminal. Curr. Dir. Psychol. Sci. 10, 224-228. 